\title{
Development of macaronic Hindi-English 'Hinglish' text message content for a coronary heart disease secondary prevention programme
}

\author{
Jay Thakkar, ${ }^{1,2,3}$ Ganesan Karthikeyan, ${ }_{1}^{4}$ Gaurav Purohit, ${ }^{4}$ Swetha Thakkar, ${ }_{1}^{5}$ \\ Jitender Sharma, ${ }^{4}$ Sunilkumar Verma ${ }_{1}{ }^{4}$ Neeraj Parakh, ${ }^{4}$ Sandeep Seth, ${ }^{4}$ \\ Sundeep Mishra, ${ }^{4}$ Rakesh Yadav, ${ }^{4}$ Sandeep Singh ${ }^{4}$ Rohina Joshi, ${ }^{1,2}$ \\ Aravinda Thiagalingam, ${ }^{2,3}$ Clara K Chow, ${ }^{1,2,3}$ Julie Redfern $^{1,2}$
}

${ }^{1}$ The George Institute for Global Health, Sydney, Australia

${ }^{2}$ Sydney Medical School, The University of Sydney, Sydney, Australia

${ }^{3}$ Westmead Hospital, Sydney, Australia

${ }^{4}$ All India Institute of Medical Sciences, New Delhi, India

${ }^{5}$ Nepean Hospital, Sydney, Australia

\section{Correspondence to} Dr Clara Chow, Level 10, King George V Building, 83-117

Missenden Rd., Camperdown, NSW 2050, Australia: cchow@georgeinstitute.org.au

Received 12 June 2016 Revised 4 September 2016 Accepted 5 September 2016

\section{ABSTRACT \\ Background Coronary heart disease (CHD) is a leading cause of morbidity and mortality in India. Text message based prevention programs have demonstrated reduction in cardiovascular risk factors among patients with CHD in selected populations. Customisation is important as behaviour change is influenced by culture and linguistic context.}

Objectives To customise a mobile phone text message program supporting behaviour and treatment adherence in CHD for delivery in North India.

Methods We used an iterative process with mixed methods involving three phases: (1) Initial translation,

(2) Review and incorporation of feedback including review by cardiologists in India to assess alignment with local guidelines and by consumers on perceived utility and clarity and (3) Pilot testing of message management software.

Results Messages were translated in three ways: symmetrical translation, asymmetrical translation and substitution. Feedback from cardiologists and 25 patients was incorporated to develop the final bank. Patients reported Hinglish messages were easy to understand $(93 \%)$ and useful (78\%). The software located in Australia successfully delivered messages to participants based in Delhi-surrounds (India).

Conclusions Our process for customisation of a text message program considered cultural, linguistic and the medical context of potential participants. This is important in optimising intervention fidelity across populations enabling examination of the generalisability of text message programs across populations. We also demonstrated the customised program was acceptable to patients in India and that a centralised cross-country delivery model was feasible. This process could be used as a guide for other groups seeking to customise their programs.

Trial registration number TEXTMEDS Australia (Parent study)—ACTRN 12613000793718.

\section{CrossMark}

To cite: Thakkar J, Karthikeyan G, Purohit G, et al. Heart Asia 2016:8:32-38.

doi:10.1136/heartasia-2016010789

\section{INTRODUCTION}

Cardiovascular disease (CVD) is a leading cause of morbidity and mortality in India. ${ }^{1}$ Surveys from India show that many patients with CVD do not receive indicated treatments ${ }^{2}{ }^{3}$ and that knowledge of CVD risk factors is relatively poor. ${ }^{4}$ Addressing this gap in CVD secondary prevention has been highlighted as a priority by international health organisations. ${ }^{5} 6$ Heath systems in low income, middle income countries like India are faced with geographical and financial barriers in providing affordable healthcare. There is need for innovative, low-cost, effective strategies that can overcome these barriers and as such a growing interest in mHealth. The Indian telecommunications network is one of the largest in the world with an estimated 997 million mobile subscribers as of September $2015^{7}$ with $42 \%$ of the subscribers from rural regions. ${ }^{7}$ The mobile tariff in India is one of the lowest in the world and incoming text messages are free of cost. These features are conducive for the development of mHealth interventions.

In recent years mobile phone text messaging has been used in patients with coronary heart disease (CHD) as a strategy to increase patient engagement, promote medication adherence, educate and support behaviour change. ${ }^{8}$ A number of studies have evaluated the role of text message based interventions in the Indian subcontinent. For example, to support medication adherence to antiretroviral therapy ${ }^{9}$ and to diabetes medications ${ }^{10}$ and for lifestyle and behaviour modification in diabetes prevention, ${ }^{11}$ mental health ${ }^{12}$ and oral health. ${ }^{13}$ However, mostly these trials employed either pictorial messages ${ }^{9}$ or English text messages. ${ }^{10}{ }^{13}$ One study that delivered text messages in the local language reported high acceptability but did not report the process of content development. ${ }^{12}$ Arguably delivery in the local vernacular is more acceptable ${ }^{14}$ and improves the capacity to assess the true potential of the intervention. Additionally the language used to support behavioural change, for example, with respect to smoking, diet and physical activity is strongly influenced by the sociocultural context.

The aim of this study was to describe the process of customisation of a secondary prevention text message program to enable delivery of this program to patients with CHD in North India. The secondary prevention text message program was originally developed for the TEXTMEDS (TEXT messages to improve MEDication adherence \& Secondary prevention-ACTRN 12613000793718) study in Australia. The TEXTMEDS trial was designed for supporting secondary prevention in Australian patients with CHD. This project was conducted in the context of upscaling for delivery of the program to patients in North India. 


\section{METHODS}

\section{Study design}

We used a three-phase mixed-methods approach to customise an existing text message support program developed in Australia into a macaronic Hinglish (Hindi-English hybrid) text message program. This involved a multistep process of translation, qualitative evaluation, feedback and pilot testing (figure 1). ${ }^{15}$ We customised the English text message bank used in the TEXTMEDS study to incorporate customs, beliefs, values and linguistic differences of the North Indian patient population. The study was conducted at the All India Institute of Medical Sciences (AIIMS) hospital (Delhi, India) in collaboration with The George Institute for Global Health (Sydney, Australia).

\begin{tabular}{|l|l|l|} 
Phase 1 & - Hinglish translation from English messages \\
Phase 2 & $\begin{array}{l}\text { Enduation by cardiologist at AIIMS Hospital } \\
\text { - Eilot testing of the software that delivered the } \\
\text { messages to participants }\end{array}$ \\
\hline
\end{tabular}

Figure 1 Developmental phases of a Hinglish text message bank. AlIMS, All India Institute of Medical Sciences.
Choice of 'Hinglish' language for the message bank

Common beliefs, behaviours, values and language use differ between Indian and Australian patients. The AIIMS hospital catchment comprises the Delhi metropolitan region, the surrounding suburbs and neighbouring states. While Hindi (official national language of India) is the most widely used language in this region, English is increasingly used as an auxiliary language. ${ }^{16}$ Under the influence of social media, marketing industry and peer pressure, English words are blending into Hindi leading to the evolution of a hybrid vernacular-'Hinglish'. ${ }^{17}$ Internet chat, mobile phones, television and word of mouth have made this a popular language for millions in the country. ${ }^{18}$ Hence, guided by the need for lucidity and ease of understanding, we opted for Hinglish based message content rather than a pure Hindi language. For example, the Hindi equivalent of words 'exercise' and 'diabetes' are 'vyaayaam' and 'madhumeha' however the English equivalent are part of mainstream vocabulary and hence were used in our customised text message bank.

\section{Phase 1: message translation}

The first phase involved translation of the TEXTMEDS message bank into Hinglish by bilingual translators with knowledge of both the Australian vernacular and the Indian context. The aim was to provide as close to identical messaging in India but account for contextual and sociocultural differences. We did not perform 'back translation'19 as the intentions were to achieve conceptual and thematic equivalence rather than direct word-to-word translation. This led to the need for modifying

Table 1 Examples of Hinglish text messages developed from the English bank for use by the Hindi-speaking Indian population

\begin{tabular}{|c|c|c|c|}
\hline Category & English text message & Hinglish equivalent & Comments \\
\hline \multirow[t]{2}{*}{ Smoking } & $\begin{array}{l}\mathrm{Hi}<\mathrm{xxx}>\text {, quitting smoking is the best thing you can do } \\
\text { to reduce your risk of a heart attack. Aim for lifetime } \\
\text { cessation today. }\end{array}$ & $\begin{array}{l}\text { Cigarette, beedi, gutkha aur tambaku ka tyag } \\
\text { (quit)—yeh sabse zyada fayda karega. Zindgi } \\
\text { bhar ke liye tyag do. }\end{array}$ & $\begin{array}{l}\text { Asymmetrical translation-incorporates } \\
\text { tobacco usage habits of the target } \\
\text { population. }\end{array}$ \\
\hline & $\begin{array}{l}\mathrm{Hi}\langle x x x>\text {, research shows that quitting smoking will } \\
\text { halve your chances of a heart attack. }\end{array}$ & $\begin{array}{l}\text { Research (anusandhaan) batate hain ke } \\
\text { bidi-cigarette-tambaku ke tyaag se heart attack } \\
\text { kaa chance aadhaa ho jaataa hai. }\end{array}$ & $\begin{array}{l}\text { Asymmetrical translation-incorporates } \\
\text { tobacco usage habits of target population. }\end{array}$ \\
\hline \multirow[t]{2}{*}{ Diet } & $\begin{array}{l}\text { Food prepared at home is usually much healthier than } \\
\text { restaurant food. Why not take food from home and } \\
\text { have an outing to the park instead? }\end{array}$ & $\begin{array}{l}\text { Ghar kaa khaanaa hotel ke khaaney se jyaadaa } \\
\text { healthy hotaa hai. Kyun na ghar se tiffin box le } \\
\text { jaayen. }\end{array}$ & Symmetrical translation. \\
\hline & $\begin{array}{l}\text { Salt is often used in packaged food by food companies } \\
\text { as a flavour enhancer or preservative and you may not } \\
\text { realise it is there. }\end{array}$ & $\begin{array}{l}\text { Readymade packet ke namkeen/paapaad/ } \\
\text { aachaar/ketchup/potato chips mein bahut } \\
\text { zyaadaa namak hota hai. Inkaa upyog kum hi } \\
\text { rakhen. }\end{array}$ & $\begin{array}{l}\text { Asymmetrical translation-provides } \\
\text { information on commonly consumed food } \\
\text { items in the target population responsible for } \\
\text { excessive salt intake. }\end{array}$ \\
\hline \multirow[t]{2}{*}{$\begin{array}{l}\text { Physical } \\
\text { activity }\end{array}$} & $\begin{array}{l}\mathrm{Hi}\langle\mathrm{xxx}\rangle \text {, usually it is safe to start mild exercise early } \\
\text { after a heart event but if you are unsure ask your doctor } \\
\text { or hospital cardiac rehab unit. }\end{array}$ & $\begin{array}{l}\text { Heart attack ke baad, halki-fulki kasrat (walking } \\
\text { exercises) se shuruat karen. Dhire dhire isme } \\
\text { badhautri karen. }\end{array}$ & $\begin{array}{l}\text { Near symmetrical translation to maintain } 160 \\
\text { character length of short message service } \\
\text { (SMS). }\end{array}$ \\
\hline & $\begin{array}{l}\mathrm{Hi}<\mathrm{xxx}>\text {, physical activity can be accumulated in short } \\
\text { bouts of } 10 \text { min each. Aim to complete } 3 \text { bouts per day. }\end{array}$ & $\begin{array}{l}\text { Ek saath } 30 \text { min yaa din me } 3 \text { baar } 10 \text { min ke } \\
\text { liye kasrat (excersie) karen. Faaydaa dono se } \\
\text { hogaa. }\end{array}$ & Symmetrical translation. \\
\hline \multirow[t]{2}{*}{ Medication } & $\begin{array}{l}\text { Aspirin stops the blood platelets from sticking and } \\
\text { prevents blood clots from forming. Take aspirin once per } \\
\text { day with food. }\end{array}$ & $\begin{array}{l}\text { Aspirin blood ko patlaa kartaa hai aur khoon ko } \\
\text { jamne se roktaa hai. Rozana pehle kuchh } \\
\text { khaanaa khayen fir aspirin ki goli len. }\end{array}$ & Symmetrical translation. \\
\hline & $\begin{array}{l}\text { Cholesterol-lowering meds have names ending with } \\
\text { statin. They help decrease low denisity lipoprotein (LDL) } \\
\text { (bad) cholesterol and increase high density lipoprotein } \\
\text { (HDL) (good) cholesterol. }\end{array}$ & $\begin{array}{l}\text { Cholesterol kum karney vali goli (medicine) ko } \\
\text { 'statin' kehtay hain. Yeah LDL namak bura } \\
\text { cholesterol kum karti hain. }\end{array}$ & $\begin{array}{l}\text { Near symmetrical translation. The last piece } \\
\text { of information on HDL cholesterol was } \\
\text { dropped to fit } 160 \text { character count. }\end{array}$ \\
\hline \multirow[t]{2}{*}{$\begin{array}{l}\text { General/ } \\
\text { guidelines }\end{array}$} & $\begin{array}{l}\text { It is important to keep LDL cholesterol levels less than } \\
\text { 2.0. }\end{array}$ & $\begin{array}{l}\text { LDL cholesterol, nuksaan-daayak (harmful) } \\
\text { cholesterol hai. Yeh khoon mein } 100 \text { mg se kum } \\
\text { honaa chaahiye. }\end{array}$ & $\begin{array}{l}\text { Symmetrical translation with education on } \\
\text { importance of } L D L \text { cholesterol. Blood levels of } \\
\text { cholesterol converted to country-specific } \\
\text { units. }\end{array}$ \\
\hline & $\begin{array}{l}\text { If you get chest pain take aspirin and anginine or } \\
\text { nitrolingual spray if you have it. Keep these medications } \\
\text { close by just in case. }\end{array}$ & $\begin{array}{l}\text { Hameshaa apne paas aspirin aur sorbitrate } \\
\text { (nitrate) goli rakhen. Chest pain ho to inkaa } \\
\text { extra dose le len aur doctor se baat karen. }\end{array}$ & $\begin{array}{l}\text { Symmetrical translation with additional } \\
\text { advice on the need to see doctor. }\end{array}$ \\
\hline
\end{tabular}

$<x x>$ represents participants preferred name. 
and/or substitution of a proportion of the text messages which were not relevant to the target population. Two bilingual researchers (JT, GP) worked independently to generate two separate drafts. These researches were medical professionals; a clinical cardiologist undertaking doctorate of philosophy (JT) and a doctor of alternative medicine (GP). The two drafts were then merged. This was further reviewed and modified by three additional bilingual clinicians/researchers (GK, ST, RJ) in order to improve clarity and the value of the content.

Messages were translated in three major ways: symmetrical translation, asymmetrical translation and substitution (table 1). The generic text messages with universal application were directly translated without modification, that is, symmetrical translation. The second group of messages required partial modification to suit local behaviours, that is, asymmetrical translation. The third group of messages was not relevant to India, for example, an English message on smoking cessation referring to an Australian website (eg, http://www.icanquit.com.au) was replaced with a Hinglish message advising the need to quit tobacco in all forms; as to our knowledge, no similar website existed in India at the time, and it was desired that information on multiple types of tobacco use was added into the message bank for India. During the translation process we also customised messages or replaced messages to integrate the sociocultural habits of the population from India, for example, while cigarette smoking is the most common means of consuming tobacco in Australia, tobacco chewing and smoking traditional hand rolled cigarettes (beedi) is equally popular in India.

Message content: The medical content of the translated text message bank aimed to be identical to the original. It covered the major areas of CVD secondary prevention including quitting tobacco, physical activity, nutrition, medication adherence, targets and monitoring of cardiovascular risk factors and general heart health information which were based on a theoretical framework. ${ }^{15}$ A wide range of behaviour change techniques was used, for example, the messages were designed to provide information, motivate, identify target goals, set up graded tasks, and encourage self-management and seeking of additional help.

Message structure: The Hinglish language used for the messages took into consideration the diversity of the audience in terms of age, sex and possible modest literacy levels. An important forethought was the need to minimise character count to $\leq 160$ (including spaces). A standard text message is of 160 character count. Longer messages are treated by most telecom companies as two messages resulting in higher cost and fragmented message delivery.

Unique challenges in translation: The screen display of all mobile phones may not be configured to support Hindi texts, however all mobile phones universally support Roman texts. Hence, we choose to deliver text that conveyed the meaning in Hindi but was worded using Roman alphabets (figure 2). This occasionally led to difficulties in accurately determining the spelling of the Hindi word. For example, there are multiple words for 'medicine' in Hindi. We selected the word 'goli' considering the ease of the spelling. However the word 'goli' can have a variety of meanings. It can signify either 'tablet' or 'bullet shot' or 'confectionary'. In order to avoid ambiguity such words were presented followed by the conventional English counterpart in parenthesis (table 1: Medication-message 2).

\section{Phase 2: evaluation and user acceptance testing}

The aim of phase 2 was to refine the content of the first draft. The initial draft bank of messages was reviewed and modified by a team of cardiologists at AIIMS hospital to ensure

\begin{tabular}{l}
..0 TPG $₹$ :21 am \\
Messages TXTMED India \\
\hline Heart attack nivaran program \\
'TEXTMEDS' mein aapka \\
swagat hain. \\
Heart attack ke baad lifestyle \\
(Jeevan-shailey) me badlaav \\
hoga. TEXTMEDS program \\
aapko sahayta dega. \\
Aspirin blood ko patla karta hain \\
aur khun ko jamne se rokta \\
hain. \\
Heart attack ke baad, halki-fulki \\
kasrat (walking) se shuruat \\
karen. Dhire dhire isme \\
badhautri karen.
\end{tabular}

Cigarette aur beedi kaa sevan
karne se heart attack kaa
chance 6 gunaa badhta hai. Aur
rupee-paise ki barbaadi alag se
hoti hai.
Muscles (maanspeshi) mein
dard cholesterol ki goli ke side

Figure 2 Prototype screenshot of a mobile phone with Hinglish messages. TEXTMEDS, TEXT messages to improve MEDication adherence \& Secondary prevention.

consistency of recommendations with local medical guidelines and appropriateness. The message bank was then distributed for feedback by end users through a participant survey. Each message was evaluated by two cardiologists and two patients with a recent diagnosis of acute coronary syndrome (ACS). Participants reported on ease of understanding and perceived usefulness of the messages. The messages were further refined based on the feedback.

\section{Phase 3: intervention delivery testing}

The finalised message bank underwent pilot testing to check compatibility and functionality of the software program used to deliver messages. The software program that administers the TEXTMEDS study was designed and is based at Westmead Hospital, a University of Sydney affiliated tertiary referral centre serving a diverse ethnic population in western Sydney, Australia. For delivering text messages to North India, the software program was modified to accommodate two changes: difference in time zone and need for communication with an India based telecom company. We were concerned that sending text messages to India through an Australian telecom company would be subject to unpredictable latency (time to end-user delivery) and risk delivery failure as messages may be treated as spam. ${ }^{20}$ Hence we used the services of a local telecom company (Delhi, India) that offered a secure communication application programming interface (API) gateway (figure 3). The messages sent were checked with India based individuals on a variety of phone networks for delivery send failure, time latency, display on handset and readability (figure 2). 


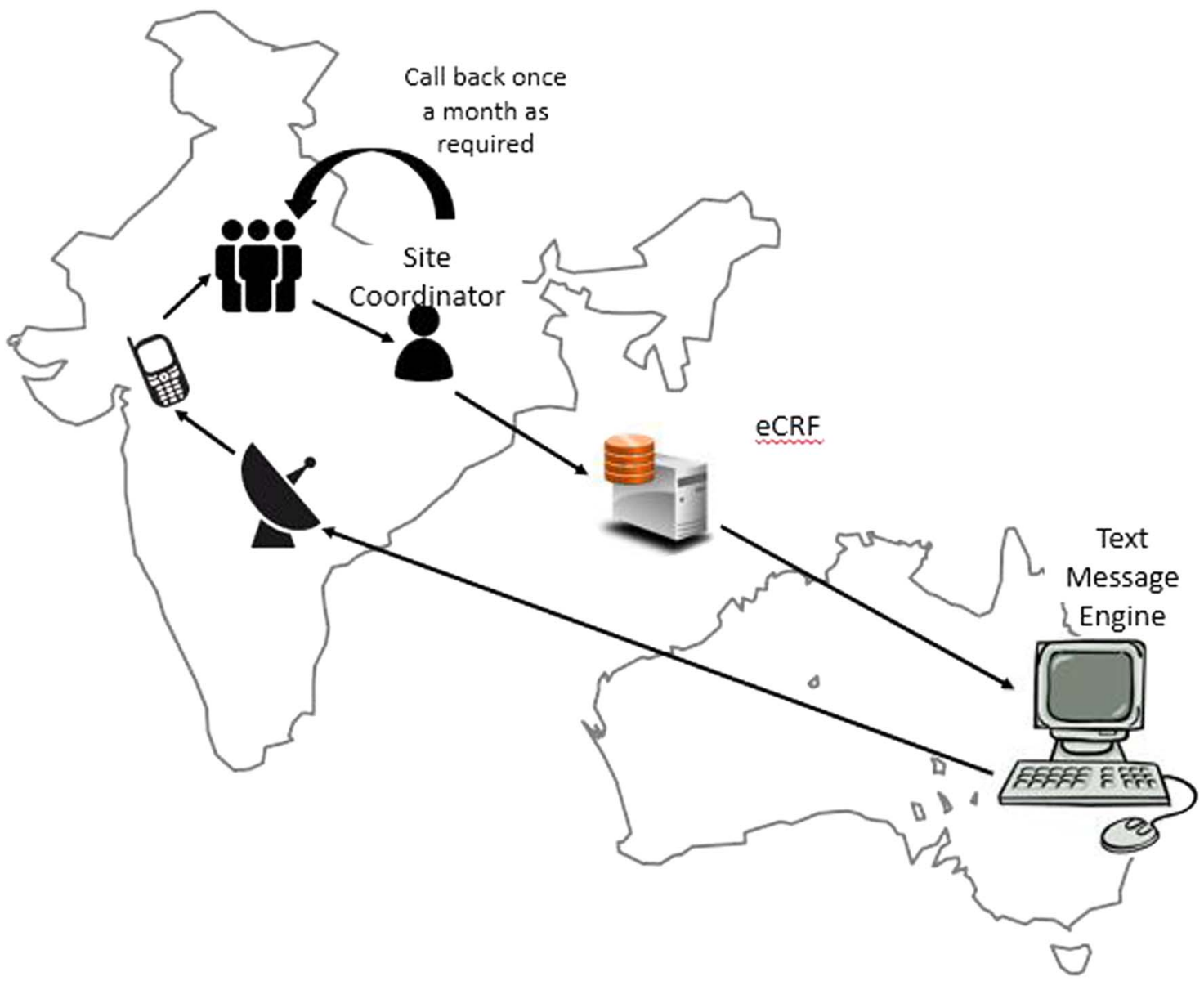

Figure 3 Operational structure of the TEXT messages to improve MEDication adherence \& Secondary prevention (TEXTMEDS) India study. The site coordinator recruits patients in Delhi (India), enters data into an eCRF (electronic case record form). This is transmitted to the text message engine based in Sydney (Australia). The engine communicates with a telecom company in India to deliver the text messages.

\section{RESULTS}

\section{Phase 1: message translation}

Table 1 illustrates examples of English text messages and their Hinglish versions. The process involved: symmetrical translation $-79 \%$, asymmetrical translation-18\% and substitution-3\%. The final bank comprised 245 Hinglish text messages. The messages provided guidance and tips on a range of key secondary prevention areas. Twenty-seven messages addressed the benefits of quitting tobacco and provided encouragement and tips for quitting. Fifty-five messages provided information on five major secondary preventative medication classes, importance of adherence and side effects. Thirty-six general cardiac messages included information on risk factor monitoring, guideline recommended targets and need for regular health check-ups. Seventy-five messages focused on nutritional facts, healthy eating habits, increasing fruit-vegetable intake, reducing salt intake and weight loss. Thirty-six messages highlighted the benefits of physical activity and establishing graded tasks. There were 16 messages comprising study welcome message, offers for additional help and study completion thank you message.

\section{Phase 2: user acceptance testing}

Patients with a recent diagnosis of ACS were approached in cardiology outpatients and inpatients for initial evaluation of the Hinglish message bank. Twenty-five participants provided feedback. Their mean age was $57 \pm 7$ years and $95 \%$ were men. All participants had completed primary school education and reported the ability to read Hindi and English. Each participant provided feedback on 20 messages and each message was reviewed by at least two participants. Participants reported 93\% were easy to understand and 78\% were perceived to be useful and informative. All participants showed good acceptance for Hinglish and none reported a need to change the text message content. Few messages required rewording; approximately five messages required significant rewording to improve clarity and understanding.

\section{Phase 3: pilot testing}

During this phase approximately 100 text messages were sent to six members of the research team and one additional external consumer. All the messages were sent during work hours (India time) on four random weekdays for 3 months. The short message service (SMS) engine located in Sydney (Australia) provided a 5-hour time offset to match with the daytime of the participants located in India. The software engine has the capacity to send 1800 text messages per hour (one SMS/2 s). The text messages were sent by the engine via a secure API gateway at no cost to participants and at a bulk rate (23 Paisa per SMS, ie, approximately $<0.01$ USD per SMS).

All seven participants reported receiving $100 \%$ of sent messages and delivery as intended. Delivery of messages at random times was viewed by these participants as a strength; avoiding habituation and desensitisation. We found the latency (time from the software sending message to the gateway to actual 


\section{Original research}

receipt by the participant) was usually within few seconds and the longest was approximately $15 \mathrm{~min}$, which was considered acceptable. All messages were displayed on the handset as intended and required no further revision.

The software engine interface (figure 4) was custom designed. It allowed the researchers to view the following (1) preferred name of the participant and their mobile phone number, (2) the summary of daily message send list, (3) the message category and its content and (4) message delivery status. The engine enabled the study team to review the detailed transaction $\log$ of each participant (figure 5).

\section{DISCUSSION}

This paper describes the process of translation and customisation of an English text message bank for use in a northern Indian population. We have outlined the key considerations

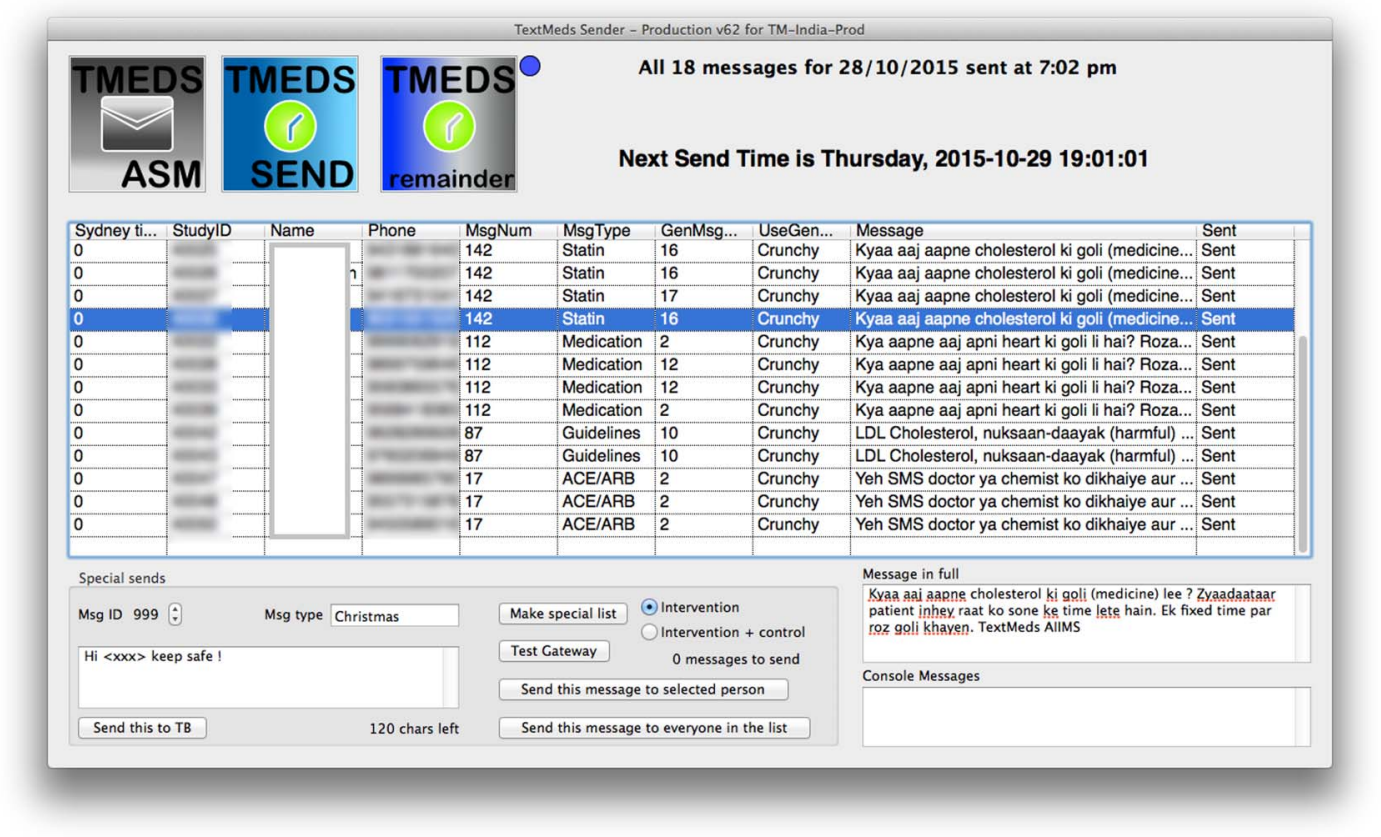

Figure 4 The 'summary' interface of the TEXT messages to improve MEDication adherence \& Secondary prevention (TEXTMEDS) engine. The main window at login provides a quick overview and ability for additional message broadcast, for example, 'Seasons Greetings' simultaneously to a large cohort.

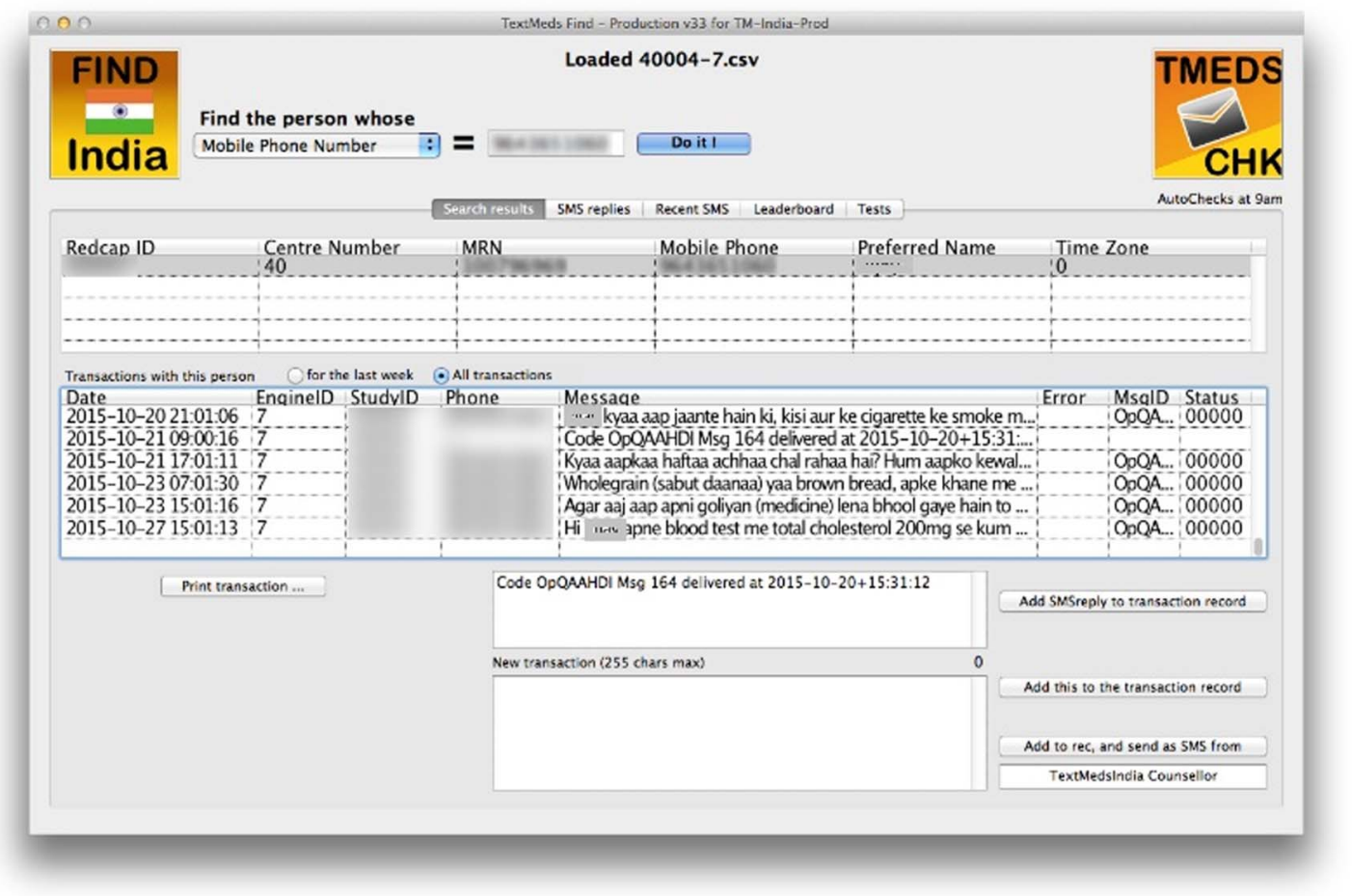

Figure 5 The 'Individual transaction log' interface of the TEXT messages to improve MEDication adherence \& Secondary prevention (TEXTMEDS) engine. 
during the development process to provide a framework for other researchers. The potential of text message based programs to support behavioural change in CHD has been described in a number of single region studies ${ }^{81}$ but to enable scale-up of these interventions, a process to customise support programmes to other populations is needed. In the current example, the process included morphing English text messages into a Hindi-English mingled version that was culturally appropriate and acceptable. We have shown that it is feasible to amalgamate two languages successfully in order to develop a macaronic text message bank which is comprehensible and acceptable to participants from non-English-speaking background of North India.

There is increasing recognition of the need to deliver linguistically and culturally appropriate healthcare programmes to non-English-speaking populations. ${ }^{14}$ In international collaborative studies, there is recognition of cultural variation and its impact on developing and customising data collection instruments. Direct translation without cultural adaptation or content equivalence can limit the utility of the intervention. Hence our team felt it was essential to maintain semantic, conceptual and experiential equivalence between the source and target language to harness the maximum potential of the intervention. ${ }^{22}$ Equivalence refers to how the piece of information relates to the intended idea across different cultures. To prove validity of such translated instruments, it is important to meticulously document the process adapted.

To our knowledge, only a small number of mHealth studies have reported their process of development of cross-cultural text message banks. ${ }^{23-25}$ Buchholz et al ${ }^{23}$ translated messages to support physical activity and Colantonio $e t$ al $l^{25}$ translated messages to support smoking cessation. Both these studies translated messages into Spanish. Hormes et $a^{26}$ have reported one problem with the translation process, that is, the target language may lack appropriate words that convey the same meaning as the source language. We did not face this problem, perhaps since our approach involved the use of a macaronic-hybrid language. Effective communication is central in a health system. Researchers and healthcare providers have the obligation to provide information in a language that participants and patients can understand.

Besides the language barrier, there are additional factors that limit access to healthcare information particularly in low income and middle income countries. This may be due to lack of infrastructure, limited access to physicians, cost associated with travel, cost of visiting health professionals and absence of awareness on need for lifelong therapy. ${ }^{3}$ Mobile phone text messaging, and other mHealth interventions, can address some of these issues. Mobile phones are increasingly used by people from all age groups, socioeconomic strata and geographical regions. This makes them attractive and cost-effective channels for health communication in low income, middle income countries. ${ }^{27}$ The cost can be further reduced by developing an integrated and centralised model for program delivery. To our knowledge most text message programs have used local telecommunications networks and delivery programs. In our study, the software engine is based in Sydney, Australia and uses a local (Indian) telecommunications company to deliver text messages. A centralised message management system like our study, requires less staff, is easy to monitor and likely more efficient. From a public health perspective, this centralised model of direct program delivery to wider and international audiences could be a low-cost means of providing individually customisable prevention and education programs in settings where resources are limited.
The main strength of our programme was involvement of bilingual translators with clinical knowledge or clinical research background. This meant that meanings and words in English were able to be converted to the Hinglish equivalents taking into account the sociocultural context and local clinical guidelines. In the absence of bilingual clinician-researchers, one approach may be to engage a professional translation service to do a first draft of the messages, then seek help of a larger group of reviewers including clinicians and consumers to ensure the message bank is consistent with clinical guidelines and uses appropriate language for local consumers. Thus if a professional translation service is engaged, it would be important that beyond direct translation, there is the additional step of integrating the sociocultural needs of the target population.

\section{CONCLUSION}

This paper describes the process of converting an English text message bank into Hinglish and the steps and potential challenges in this. Ensuring prevention programmes focused on education and support are appropriately customised for populations are likely to be important in preserving the fidelity of intervention delivery across populations. In the current case a hybrid language text message bank was developed. Internationalisation facilitated by mHealth may mean that in the future world of mHealth, such languages become the norm and certainly with

\section{Key messages}

What is already known about this subject?

- Mobile phone text messaging can positively influence behaviour and reduce risk in patients with coronary heart disease (CHD), however much of the current data come from English-speaking countries.

- There is increasing recognition of the need to deliver linguistically and culturally appropriate healthcare education to non-English-speaking populations.

- Health systems in low income, middle income countries like India are faced with additional challenges like financial and geographical barriers in providing secondary preventative programmes for patients with CHD and in this context mHealth is viewed as a promising tool.

\section{What does this study add?}

- This study reports a systematic process for customisation and implementation of cultural and linguistically appropriate mHealth intervention for use in patients with Hindi as the first language.

- This study has shown that a hybrid language can be an acceptable mode of communication.

- This study documents cross-country programme delivery supporting feasibility of a centralised model for programme delivery.

How might this impact on clinical practice?

- The study is a guide for future authors customising and upscaling mHealth interventions for low income, middle income non-English-speaking countries.

- A centralised model for programme delivery across multiple countries can be efficient and can lower the overall cost of the programme. This can be an attractive strategy for international health organisations (like WHO) considering wider delivery of mHealth interventions. 
much existing cross-cultural dialogue this is already the norm. Our experience has demonstrated high acceptance and comprehension for such hybrid messages by consumers. We have also demonstrated the feasibility of cross-country programme delivery. Centralised models that enable international delivery of programmes may be potentially used for large-scale implementation of mobile technology-based public health interventions.

Acknowledgements The authors thank all cardiologists and patients at AllMS hospital who participated in the evaluation of the text message bank and provided their valued opinion. The authors also thank their software engineer Tony Barry for his ceaseless efforts for the development of text message engine software and Alistair McEwan for providing additional technical support; Sandeep Prasad (Nimbus IT) whose telecommunications support was crucial for project initiation at AlIMS Hospital; and Bhupendra Thakkar for facilitating pilot testing.

Contributors CKC, AT, JR conceptualised and designed the original TEXTMEDS study (parent study). CKC, AT, JR, JT, GK furthered and customised the concept for scientific application in the Hindi-speaking population. JT, ST, GK, GP, JS, SV, NP, SS, RJ facilitated the development of the Hinglish message bank through a multistage iterative process. GK, GP, JS, SV, NP, SS facilitated evaluation of the message bank among the target population. JT wrote the first draft of the manuscript. All authors contributed to critical revision and gave final approval of the submitted version.

Funding The TEXTMEDS study in Australia is supported by the National Health and Medical Research Council (NHMRC) of Australia (ID APP1042290).

Competing interests JT is a PhD student at The University of Sydney and recipient of Australian postgraduate award scholarship. RJ is funded by a Future Leader Fellowship funded by the National Heart Foundation (APP100484). CKC is funded by the Career Development Fellowship cofunded by the NHMRC and National Heart Foundation and Sydney Medical Foundation Chapman Fellowship (1033478). JR is funded by a Career Development and Future Leader Fellowship cofunded by the National Health and Medical Research Council and the National Heart Foundation (APP1061793).

Ethics approval AllMS hospital ethics committee-Indian Council of Medical Research (Number: 50/5/IF-CVD/2013-NCD-II).

Provenance and peer review Not commissioned; internally peer reviewed.

\section{REFERENCES}

1 Jha $P$, Nugent $R$, Verguet $S$, et al. Disease control priorities in developing countries, 3rd edition. Working paper\#2. 11 June, 2013. Disease Control Priorities project. http://www.dcp-3.org/

2 Joshi R, Chow CK, Raju PK, et al. Fatal and nonfatal cardiovascular disease and the use of therapies for secondary prevention in a rural region of India. Circulation 2009;119:1950-5.

3 Yusuf S, Islam S, Chow CK, et al. Use of secondary prevention drugs for cardiovascular disease in the community in high-income, middle-income, and low-income countries (the PURE Study): a prospective epidemiological survey. Lancet 2011;378:1231-43.

4 Zaman MJ, Patel A, Jan S, et al. Socio-economic distribution of cardiovascular risk factors and knowledge in rural India. Int J Epidemiol 2012;41:1302-14.

5 Yusuf S, Wood D, Ralston J, et al. The World Heart Federation's vision for worldwide cardiovascular disease prevention. Lancet 2015;386:399-402.

6 Wood D, Mendis S, Ebrahim S, et al. Paper 4: Research Priorities Prevention and control of cardiovascular disease with a focus on Low and Middle Income Countries. Working paper series. WHO Meetings on Development of a prioritized Research Agenda for Prevention and Control of noncommunicable Diseases 2008, 2009, 2010. Geneva: World Health Organization, October 2010.
7 Highlights of telecom subscription data as on 30th September 2015. Telecom Regulatory Authority India. Press release 65/2015, 18th November 2015. http:// www.trai.gov.in/WriteReadData/WhatsNew/Documents/PR_No.65_TSD_Sep_15.pdf (accessed 20 Sept 2016).

8 Chow CK, Redfern J, Hillis GS, et al. Effect of lifestyle-focused text messaging on risk factor modification in patients with coronary heart disease: a randomized clinical trial. JAMA 2015;314:1255-63.

9 Rodrigues R, Shet A, Antony J, et al. Supporting adherence to antiretroviral therapy with mobile phone reminders: results from a cohort in South India. PLOS ONE 2012; 7:e40723.

10 Shetty AS, Chamukuttan S, Nanditha A, et al. Reinforcement of adherence to prescription recommendations in Asian Indian diabetes patients using short message service (SMS)—a pilot study. J Assoc Physicians India 2011;59:711-14.

11 Ram J, Selvam S, Snehalatha C, et al. Improvement in diet habits, independent of physical activity helps to reduce incident diabetes among prediabetic Asian Indian men. Diabetes Res Clin Pract 2014;106:491-5.

12 Chandra PS, Sowmya HR, Mehrotra S, et al. 'SMS' for mental health-feasibility and acceptability of using text messages for mental health promotion among young women from urban low income settings in India. Asian J Psychiatr 2014; 11:59-64.

13 Sharma R, Hebbal M, Ankola AV, et al. Mobile-phone text messaging (SMS) for providing oral health education to mothers of preschool children in Belgaum City. J Telemed Telecare 2011;17:432-6.

14 National Standards for Culturally and Linguistically appropriate services in Health and Health care. March 2001. US department of Health and Human services. http:// minorityhealth.hhs.gov/assets/pdf/checked/finalreport.pdf (accessed 20 Oct 2015).

15 Redfern J, Thiagalingam A, Jan S, et al. Development of a set of mobile phone text messages designed for prevention of recurrent cardiovascular events. Eur J Prev Cardiol 2014;21:492-9.

16 Bansal RK. The pronunciation of English in India. In: Susan Ramsaran. Studies in the Pronouncation of English. A commemorative volume in the Honour of A.C. Gimson. Routledge library editions. The English language, 2015.

17 Kothari R, Snell R. Chutnefying English. The Phenomena of Hinglish. Penguin Books, 2011

18 Scott Baldauf. A Hindi-English Jumble spoken by 350 million. The christian Science Monitor. 2004. http://www.csmonitor.com/2004/1123/p01s03-wosc.html (accessed 5 Oct 2015).

19 Sousa VD, Rojjanasrirat W. Translation, adaptation and validation of instruments or scales for use in cross-cultural health care research: a clear and user-friendly guideline. J Eval Clin Pract 2011;17:268-74.

20 Telecom Regulatory Authority of India. The Telecom commercial communications customer preference regulations, 2010. No. 305-17 / 2010. 1st December, 2010. file://C:/Users/Jay/Downloads/201205301159277252627regulation1dec2010.pdf. (accessed 20 Sept 2016).

21 Pfaeffli Dale L, Whittaker R, Jiang Y, et al. Text Message and Internet Support for Coronary Heart Disease Self-Management: Results From the Text4Heart Randomized Controlled Trial. J Med Internet Res 2015;17:e237.

22 Daniel M, Miller A, Wilbur J. Multiple Instrument Translation for Use with South Asian Indian Immigrants. Res Nurs Health 2011;34:419-32.

23 Buchholz SW, Sandi G, Ingram D, et al. Bilingual Text Messaging Translation: Translating Text Messages From English Into Spanish for the Text4Walking Program. JMIR Res Protoc 2015;4:e51.

24 Kolodziejczyk JK, Norman GJ, Barrera-Ng A, et al. Feasibility and effectiveness of an automated bilingual text message intervention for weight loss: pilot study. JMIR Res Protoc 2013;2:e48.

25 Colantonio LD, Peña L, Whittaker R, et al. Cross-cultural adaptation of a text message-based program for smoking cessation in Buenos Aires, Argentina. Nicotine Tob Res 2016;18:314-20.

26 Hormes JM, Rozin P. Does "craving" carve nature at the joints? Absence of a synonym for craving in many languages. Addict Behav 2010;35:459-63.

27 Deglise C, Suggs LS, Odermatt P. SMS for disease control in developing countries: a systematic review of mobile health applications. J Telemed Telecare 2012;18:273-81. 